\title{
Vector control of three-phase AC/DC front-end converter
}

\author{
J S SIVA PRASAD, TUSHAR BHAVSAR, RAJESH GHOSH and \\ G NARAYANAN
}

Department of Electrical Engineering, Indian Institute of Science, Bangalore 560012

e-mail: prasad@ee.iisc.ernet.in; tusharbhavsar@ rediffmail.com; rajesiisc@yahoo.co.in; gnar@ee.iisc.ernet.in

\begin{abstract}
A vector control scheme is presented for a three-phase AC/DC converter with bi-directional power flow capability. A design procedure for selection of control parameters is discussed. A simple algorithm for unit-vector generation is presented. Starting current transients are studied with particular emphasis on high-power applications, where the line-side inductance is low. A starting procedure is presented to limit the transients. Simulation and experimental results are also presented.
\end{abstract}

Keywords. Ac-dc conversion; controlled rectification; power factor correction; PWM converter; synchronous reference frame control; vector control.

\section{Introduction}

A three-phase AC to DC converter is an essential part of many power electronic systems such as uninterruptible power supplies (UPS), battery chargers and motor drives. The battery charger needs ac-dc conversion, while UPS and motor drives typically have an ac-dc conversion stage followed by dc-ac conversion.

Traditionally diode rectifiers are used for ac-dc conversion. These rectifiers can only produce a constant DC voltage, which is a function of the system voltage. A thyristor rectifier can be used to produce variable dc output voltage. But, both these rectifiers behave as nonlinear loads. The currents drawn by the rectifiers include a fundamental (or line frequency) component and harmonic components. The voltage drop across the line inductance due to the harmonic currents distorts the mains voltage. Consequently, the other loads connected to the mains are also fed with a distorted voltage.

Figure 1 illustrates such harmonic pollution of the mains considering a single-phase rectifier load. This is true for a three-phase system also. Figure $1 \mathrm{~b}$ shows an oscillogram of the distorted mains voltage, which is typical when non-linear loads are connected. Note that the waveform is flat close to the peaks, unlike a sinusoidal waveform. The distortion will be higher, if the non-linear load is of higher rating or several such non-linear loads are connected in parallel.

A pulse width modulated (PWM) rectifier, such as the one shown in figure 2, draws near sinusoidal currents from the ac mains. Also, the dc output voltage can be regulated, and the 


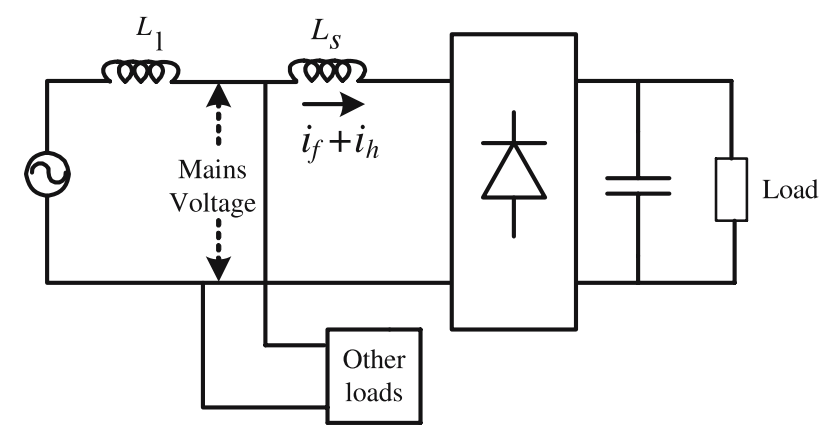

(a)

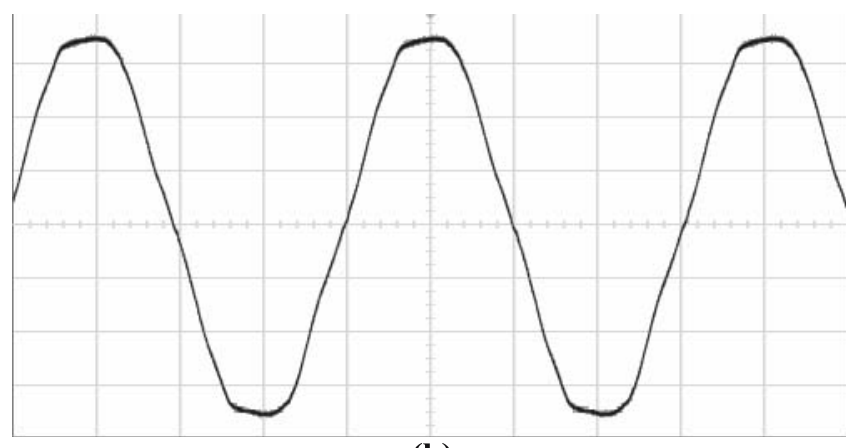

(b)
Figure 1. Harmonic pollution due to a non-linear load (a) a typical circuit connection, (b) distorted mains voltage.

input power factor is adjustable. For the converter shown in figure 2, the power can also flow in either direction, which is required in many motor drive applications. Since the converter is typically connected in the line-side of a motor drive, this is called a line-side converter or front-end converter (FEC).

The converter consists of a three-phase bridge, a high capacitance on the dc side and a three-phase inductor in the line-side. The voltage at the mid point of a leg or the pole voltage $v_{i}$ is pulse width modulated (PWM) in nature. The pole voltage consists of a fundamental component (at line frequency) besides harmonic components around the switching frequency of the converter. Being at high frequencies, these harmonic components are well filtered by the line inductor. Hence the current is near sinusoidal. The fundamental component of $v_{i}$ controls the flow of real and reactive power.

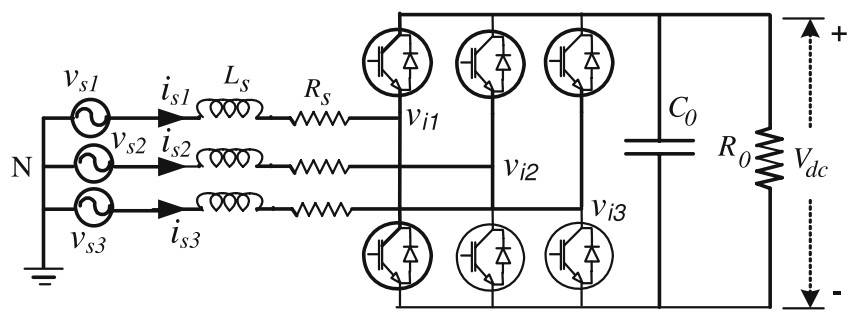

Figure 2. Schematic diagram of a front-end converter (FEC). 


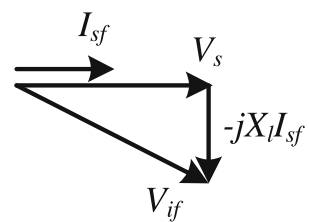

(a)

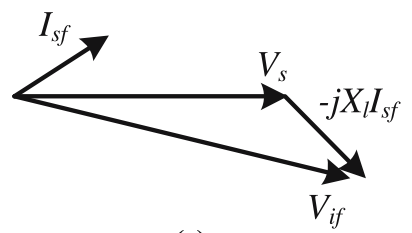

(c)

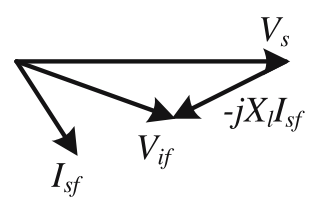

(b)

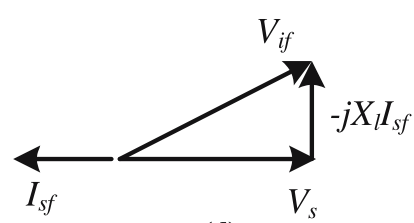

(d)
Figure 3. Phasor diagrams of an FEC under different operating modes (a) unity pf, (b) lagging pf, (c) leading pf and (d) regeneration at unity $\mathrm{pf}$.

It is well known that the active power flows from the leading voltage to the lagging voltage and the reactive power flows from the higher voltage to the lower voltage. Therefore, both active and reactive power can be controlled by controlling the phase and magnitude of the converter voltage fundamental component with respect to the grid voltage. Figure 3 shows the phasor diagrams of the converter under different modes of operation. In this figure, the subscript ' $f$ ' indicates the fundamental component of that particular quantity. Figure $3 \mathrm{a}$ illustrates the operation at unity power factor. As the grid voltage leads the converter pole voltage, real power flows from the ac side to the dc side. Figure $3 \mathrm{~b}$ corresponds lagging power factor operation. The real power flows from the ac to the dc side. Since $V_{s}$ is greater than $V_{i}$, the reactive power flows from the mains to the converter side. In figure $3 \mathrm{c}$ (leading power factor), the real power flows from the ac to the dc side, while the reactive power flows from the converter to the grid. Figure $3 \mathrm{~d}$ shows the operation under regenerative mode with the real power flowing from the dc to the ac side and at unity power factor.

Apart from control of real and reactive power flow, an FEC should also have a fast dynamic response. Several control schemes have been reported in the literature for FEC (Chattopadhyay \& Ramanarayanan 2005; Ghosh 2007; Noguchi et al 1998). This paper discusses vector control of the FEC.

Vector control is a popular method for control of three-phase induction motors. The basic idea of this scheme is to control the flux producing and the torque-producing components of motor current in a decoupled manner to achieve fast dynamic response (Leonhard 2001; Ranganathan 2007). The outer control loop controls the speed of the motor, while the inner loop controls the components of current vector, which correspond to torque and flux.

Similar control approach can be used for FEC also. Here, the three-phase grid voltages and line currents are converted into an equivalent two-phase system, called stationary reference frame. These quantities are further transformed into a reference frame called synchronous reference frame, which revolves at the grid frequency. These transformations are explained in $\S 2$. In synchronous reference frame, the components of current corresponding to active and reactive power are controlled in an independent manner similar to the torque and flux producing components in a motor drive. The outer loop controls the dc bus voltage and the inner loop controls the line currents. The control method is presented in $\S 2$. The selection of controller parameters is discussed in $\S 3$. Section 4 presents the simulation and experimental results of FEC. Section 5 discusses the problems associated with the starting process of an FEC, particularly at high power levels and the proposed solutions. Section 6 gives the conclusions. 


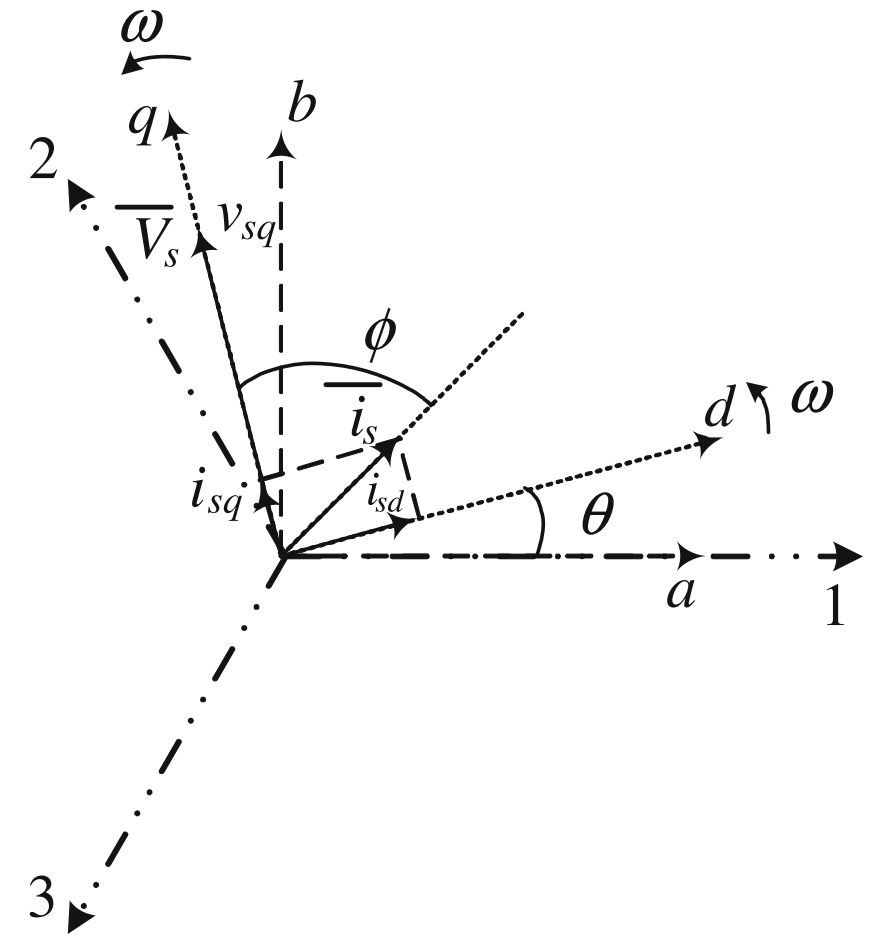

Figure 4. Stationary and synchronously revolving frames of reference.

\section{Vector control of FEC}

The FEC, shown in figure 2 is fed from the ac mains. Mains voltages $v_{s 1}, v_{s 2}$ and $v_{s 3}$ are defined in (1), where $V_{s}$ is the rms value of phase to neutral voltage. The three-phase voltages can be transformed into two-phase quantities $v_{s a}$ and $v_{s b}$, which are the components of voltage vector $\bar{V}_{s}$ along $a$-axis and $b$-axis, respectively, in the stationary reference frame (figure 4).

$$
\begin{aligned}
& v_{s 1}=\sqrt{2} V_{s} \cos \omega t \\
& v_{s 2}=\sqrt{2} V_{s} \cos \left(\omega t-120^{0}\right) \\
& v_{s 3}=\sqrt{2} V_{s} \cos \left(\omega t-240^{0}\right) \\
& v_{s a}=\frac{3}{2} v_{s 1}=\frac{3}{2} \sqrt{2} V_{s} \cos \omega t \quad v_{s b}=\frac{\sqrt{3}}{2}\left(v_{s 2}-v_{s 3}\right)=\frac{3}{2} \sqrt{2} V_{s} \sin \omega t .
\end{aligned}
$$

These voltages can further be transformed into a synchronously revolving $d-q$ reference frame, where $q$-axis is aligned with the voltage vector $\bar{V}_{s}$ and the $d$-axis lags the $q$-axis by $90^{\circ}$ as shown in figure 4. This transformation is performed using (3), where $\theta$ is the angle of the $d$-axis measured from the $a$-axis. The other three-phase quantities, namely line currents $\left(i_{s 1}\right.$, $i_{s 2}$ and $\left.i_{s 3}\right)$ and the converter pole voltages $\left(v_{i 1}, v_{i 2}\right.$ and $\left.v_{i 3}\right)$, can also be similarly transformed 


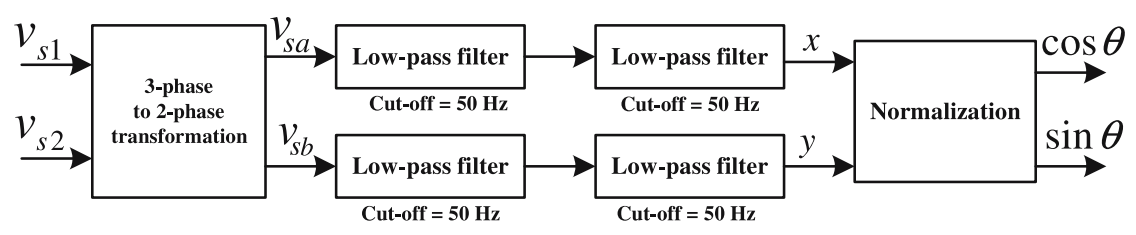

Figure 5. Unit vector generation.

to the $d-q$ reference frame.

$$
\begin{aligned}
& v_{s q}=\left(-v_{s a} \sin \theta+v_{s b} \cos \theta\right) \\
& v_{s d}=\left(v_{s a} \cos \theta+v_{s b} \sin \theta\right) .
\end{aligned}
$$

The voltage equations of the FEC in the $d-q$ reference frame are given by (4), where $R_{s}$ and $L_{s}$ are the resistance and inductance, respectively, of the line inductor.

$$
\begin{aligned}
& R_{s} i_{s d}+L_{s} \frac{d i_{s d}}{d t}-\omega L_{s} i_{s q}+v_{i d}=0 \\
& R_{s} i_{s q}+L_{s} \frac{d i_{s q}}{d t}+\omega L_{s} i_{s d}+v_{i q}=v_{s q} .
\end{aligned}
$$

\subsection{Unit vector generation}

In order to transform any vector from stationary reference frame into $d-q$ reference frame, the quantities $\sin \theta$ and $\cos \theta$, which are the components of a revolving unit vector are required (see equation 3 ). These quantities should have the same frequency as that of the system voltage.

The voltage vector $\bar{V}_{s}$ is at an angle $\omega t$ (see equation (1)) with respect to the $a$-axis. The components $v_{s a}$ and $v_{s b}$ of the vector are as shown in (2). A low-pass filter, whose corner frequency equals the mains frequency, delays $v_{s a}$ (or $v_{s b}$ ) by $45^{\circ}$. Two such filters in cascade delay $v_{s a}$ (or $v_{s b}$ ) by $90^{\circ}$ as shown in (5). Figure 5 illustrates such a filter arrangement followed by normalization as given by (6). Such filtering and normalization yields $\cos \theta$ and $\sin \theta$, where $\theta$ is the angle between $a$-axis and $d$-axis required for the transformation in (3).

Such a method of unit vector generation [equations (5)-(6) and figure 5] is more straightforward than the use of phase-locked loops (PLL) (Chung 2000).

$$
\begin{aligned}
& x=\frac{3}{4} \sqrt{2} V_{s} \cos \left(\omega t-\frac{\pi}{2}\right)=\frac{3}{4} \sqrt{2} V_{s} \cos \theta \\
& y=\frac{3}{4} \sqrt{2} V_{s} \sin \left(\omega t-\frac{\pi}{2}\right)=\frac{3}{4} \sqrt{2} V_{s} \sin \theta \\
& \cos \theta=\frac{x}{\sqrt{x^{2}+y^{2}}} \quad \sin \theta=\frac{y}{\sqrt{x^{2}+y^{2}}} .
\end{aligned}
$$

In the above discussion, it is assumed that the grid voltages are free from harmonics, grid frequency remains unchanged at $50 \mathrm{~Hz}$ and grid voltages are balanced. The performance of 
Table 1. Effect of frequency variation on unit vector generation.

\begin{tabular}{lcccc}
\hline $\begin{array}{l}\text { Line } \\
\text { Frequency } \\
(\mathrm{Hz})\end{array}$ & $\begin{array}{c}\text { Magnitude of } \\
\text { unit-vector }\end{array}$ & $\begin{array}{c}\text { Phase } \\
\text { error }(\delta)\end{array}$ & $\begin{array}{c}v_{s q}= \\
\cos \delta(\mathrm{p} . \mathrm{u})\end{array}$ & $\begin{array}{c}v_{s d}= \\
\sin \delta(\mathrm{p} . \mathrm{u})\end{array}$ \\
\hline 48 & 1 & -2.34 & 0.99 & -0.04 \\
49 & 1 & -1.157 & 0.99 & -0.02 \\
50 & 1 & 0 & 1 & 0 \\
51 & 1 & 1.1345 & 0.99 & 0.02 \\
52 & 1 & 2.246 & 0.99 & 0.04 \\
\hline
\end{tabular}

unit vector generation scheme under the presence of harmonics in grid voltage, grid frequency variation and unbalance in grid voltages is studied below.

2.1a Grid voltage harmonics: In unit-vector generation algorithm, $v_{s a}$ and $v_{s b}$ are passed through two cascaded low-pass filters with $50 \mathrm{~Hz}$ corner frequency. Ignoring any variation in the line frequency, the combined gain of the two-cascaded filters for $n^{\text {th }}$ harmonic voltage is given by

$$
A_{n}=\left|\frac{1}{1+j n}\right|^{2}=\frac{1}{1+n^{2}} .
$$

The $5^{\text {th }}$ and $7^{\text {th }}$ harmonics are attenuated to $3.85 \%$ and $2 \%$ respectively, of their original values. The attenuation is still higher for harmonics such as $11^{\text {th }}, 13^{\text {th }}, 17^{\text {th }}$, etc. Thus, the components of the unit vector are practically devoid of any harmonic content. The unit vector generation algorithm works satisfactorily even in the presence of harmonics in the grid voltage.

2.1b Grid frequency variation: The gain and the phase of the low-pass filters used in unit vector generation (figure 5) change with the supply frequency. The normalization (6) ensures that the magnitude of unit vector generated is unaffected by line frequency variation. However, the phase angle between $v_{s a}$ and $x$, and that between $v_{s b}$ and $y$ are no longer equal to $90^{\circ}$. The errors in the phase angle are as tabulated in table 1, for line frequencies in the range of 48 to $52 \mathrm{~Hz}$. The corresponding errors in $v_{s q}$ and $v_{s d}$ are also shown in table 1 . It can be observed that the error in $v_{s q}$ is less than $1 \%$, while the error in $v_{s d}$ is less than $4 \%$. Hence, it can be concluded that variation of grid frequency within the given range only has a marginal effect on unit vector generation.

2.1c Grid voltage unbalance: With unbalance in grid voltages, $v_{s 1}, v_{s 2}$ and $v_{s 3}$ of figure 2, can be expressed as shown in (8), where $A$ is the amplitude of positive sequence voltage, $B$ is the amplitude of the negative sequence voltage, $C$ is the amplitude of zero sequence voltage, and $\lambda$ is the phase angle of the zero-sequence component.

$$
\begin{aligned}
& v_{s 1}=A \cos \omega t+B \cos \omega t+C \cos (\omega t-\lambda) \\
& v_{s 2}=A \cos \left(\omega t-120^{\circ}\right)+B \cos \left(\omega t-240^{\circ}\right)+C \cos (\omega t-\lambda) \\
& v_{s 3}=A \cos \left(\omega t-240^{\circ}\right)+B \cos \left(\omega t-120^{\circ}\right)+C \cos (\omega t-\lambda) .
\end{aligned}
$$


The components of the voltage vector along $a$ and $b$ axes are given by

$$
\begin{aligned}
& v_{s a}=\left(\frac{3}{2}\right)[(A+B) \cos \omega t+C \cos (\omega t-\lambda)] \\
& v_{s b}=\left(\frac{3}{2}\right)(A-B) \sin \omega t .
\end{aligned}
$$

The outputs of cascaded low-pass filters, namely $x$ and $y$ (figure 5), can be expressed as

$$
\begin{aligned}
& x=\left(\frac{3}{4}\right)[(A+B) \sin \omega t+C \sin (\omega t-\lambda)] \\
& y=-\left(\frac{3}{4}\right)(A-B) \cos \omega t .
\end{aligned}
$$

For generating the unit-vector, $x$ and $y$ are normalized as shown in figure 5. The quantity $x^{2}+y^{2}$ can be expressed as

$$
\begin{aligned}
x^{2}+y^{2}= & \left(\frac{3}{4}\right)^{2}\left(A^{2}+B^{2}+\frac{C^{2}}{2}+[(A+B) C \cos \lambda]\right) \\
& -\left(\frac{3}{4}\right)^{2}[2 A B \cos 2 \omega t+\{(A+B) C \cos (2 \omega t+\lambda)\}] .
\end{aligned}
$$

The unit vector can be expressed as

$$
\begin{aligned}
& \bar{F}_{u}=\frac{x}{\sqrt{x^{2}+y^{2}}}+j \frac{y}{\sqrt{x^{2}+y^{2}}} \\
& \left|\bar{F}_{u}\right|=1, \quad \angle \bar{F}_{u}=\tan ^{-1}\left(\frac{y}{x}\right) .
\end{aligned}
$$

The magnitude of the unit vector generated is equal to one. However, the phase angle of the unit vector, which must be equal to $\omega t$ (in stationary reference frame), does not change linearly with time under steady state due to voltage imbalance. The deviation between the phase of the unit vector and $\omega t$ is low only when $B$ and $C[(8)-(11)]$ are low.

Thus, the performance of unit vector generation scheme is satisfactory in the presence of line harmonics and over a range of line frequencies. However, in the presence of voltage imbalance, its performance is satisfactory only when the imbalance is marginal. The proposed control scheme itself is mainly suited for operation under balanced input voltages. Control of PWM rectifier under voltage imbalance conditions requires modification in the control scheme and has been discussed in literature (Chattopadhyay \& Ramanarayanan 2005; Ghosh 2007).

\subsection{Vector control approach}

The overall block diagram of a vector controlled FEC is shown in figure 6 . The mains voltages and the line currents are transformed into $d-q$ reference frame, and are used as feedback variables for the controller as shown in the figure. The control calculations are performed in the $d-q$ reference frame. 


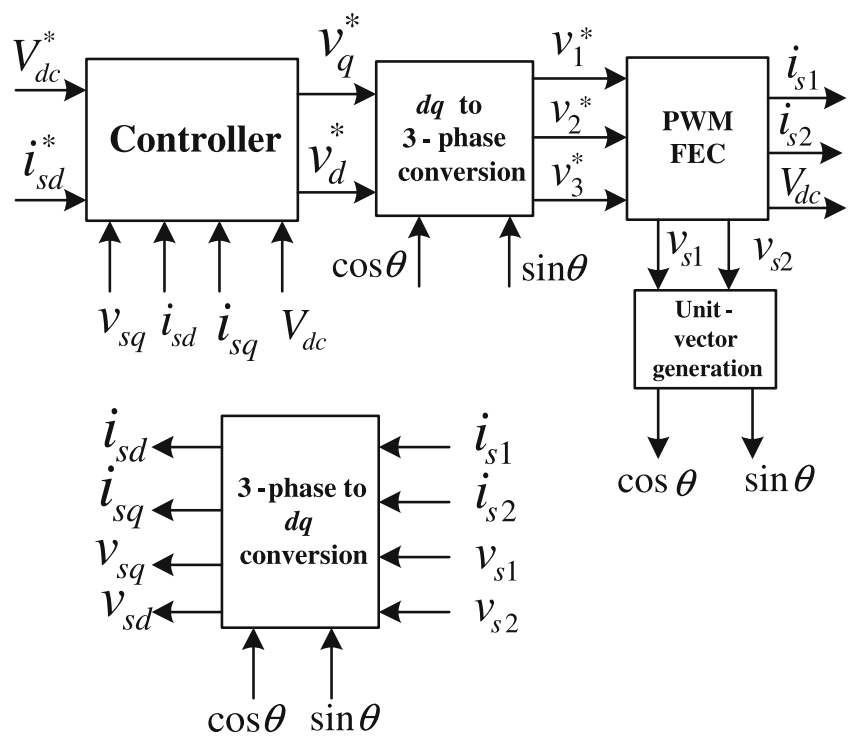

Figure 6. Block diagram of a vector controlled front-end converter.

The vector controller has an outer voltage loop to control $V_{d c}$. The voltage controller sets the reference to the inner $q$-axis current controller as shown in figure 7 . The $q$-axis current loop controls the flow of real power $p$, since $i_{s q}$ is a measure of $p$ as shown in (14a). There is an independent loop for the control of $i_{s d}$, which controls reactive power as per (14b).

$$
\begin{aligned}
& p=\frac{2}{3}\left(v_{s q} i_{s q}+v_{s d} i_{s d}\right)=\frac{2}{3}\left(v_{s q} i_{s q}\right) \\
& q=\frac{2}{3}\left(v_{s q} i_{s d}-v_{s d} i_{s q}\right)=\frac{2}{3}\left(v_{s q} i_{s d}\right) .
\end{aligned}
$$

\subsection{Feedforward terms}

A cross coupling exists between the $d$-axis and the $q$-axis quantities as seen from (4). To ensure decoupled control of $i_{s d}$ and $i_{s q}$, feedforward terms $v_{d f f}$ and $v_{q f f}$ respectively, are added to the outputs of the $d$-axis controller $\left(v_{i d}^{\prime \prime}\right)$ and the $q$-axis controller $\left(v_{i q}^{\prime \prime}\right)$ as given in (15) and illustrated in figure 7. The converter gain $G$ is defined in (16), where $V_{c}$ is the peak

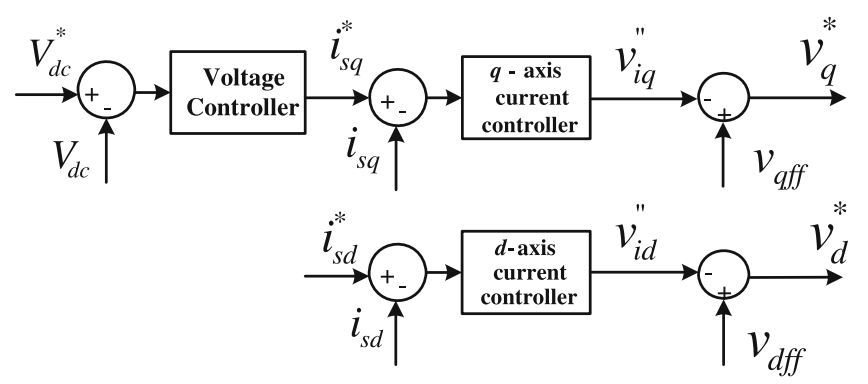

Figure 7. Voltage and current controllers in a vector controlled front-end converter. 


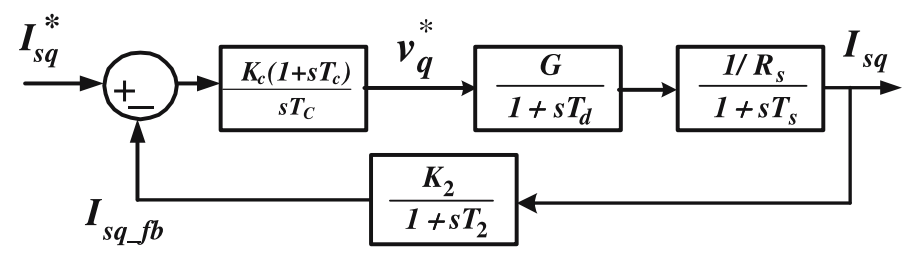

Figure 8. Current controller.

of the triangular carrier used in sine-triangle PWM.

$$
\begin{aligned}
& v_{d}^{*}=-v_{i d}^{\prime \prime}+v_{d f f}=-v_{i d}^{\prime \prime}+\frac{\omega L_{s} i_{s q}}{G} \\
& v_{q}^{*}=-v_{i q}^{\prime \prime}+v_{q f f}=-v_{i q}^{\prime \prime}+\frac{v_{s q}}{G}-\frac{\omega L_{s} i_{s d}}{G} \\
& G=\frac{V_{d c}}{2 V_{c}} .
\end{aligned}
$$

The above controller ensures that the current loop has a first order response as given by (17).

$$
\begin{aligned}
& R_{s} i_{s d}+L_{s} \frac{d i_{s d}}{d t}=G v_{i d}^{\prime \prime} \\
& R_{s} i_{s q}+L_{s} \frac{d i_{s q}}{d t}=G v_{i q}^{\prime \prime} .
\end{aligned}
$$

The voltage references, $v_{q}^{*}$ and $v_{d}^{*}$ are transformed into three-phase references $\left(v_{1}^{*}, v_{2}^{*}, v_{3}^{*}\right)$ using the inverse of the transformations in (3) and (2).

\section{Design of controllers}

This section explains the selection of controller parameters for the voltage and current loops.

\subsection{Current controller}

The converter is modelled using its gain $G$ and the delay time $T_{d}$ as shown in figure 8 . The delay $T_{d}$ is equal to half the time period of the carrier signal. A block diagram of the $q$-axis current loop is shown in figure 8, where $T_{s}$ is the time constant of the inductor $\left(T_{s}=L_{S} / R_{S}\right)$, and $K_{2}$ and $T_{2}$ are the gain and time constant, respectively, of the current sensor.

The open loop transfer function between $I_{s q_{-} f b}$ and $v_{q}^{*}$ can be approximated as shown in (18), since $T_{d} T_{2}$ is very small. Here $T_{\sigma}=T_{d}+T_{2}$.

$$
\frac{I_{s q_{-} f b}(s)}{v_{q}^{*}(s)}=\frac{G K_{2}}{R_{s}} \frac{1}{\left(1+s T_{s}\right)\left(1+s T_{d}\right)\left(1+s T_{2}\right)} \cong \frac{G K_{2}}{R_{s}} \frac{1}{\left(1+s T_{s}\right)\left(1+s T_{\sigma}\right)} .
$$

Since $T_{s}$ is much higher than $T_{\sigma}$, this pole at $\left(1 / T_{s}\right)$ is cancelled using the controller zero by choosing controller parameter $T_{c}$ as shown in (19).

$$
T_{c}=T_{s} .
$$


The resulting closed loop transfer function is given by (20), where $T_{d} T_{2}$ is neglected once again.

$$
\frac{I_{s q}(s)}{I_{s q}^{*}(s)}=\frac{K_{c} G}{R_{s} T_{s} T_{\sigma}} \frac{\left(1+s T_{2}\right)}{\left(s^{2}+\frac{s}{T_{\sigma}}+\frac{K_{c} G K_{2}}{R_{s} T_{s} T_{\sigma}}\right)} .
$$

Comparing the denominator of R.H.S of (20) with the standard form of second order transfer function

$$
2 \xi \omega_{n}=\frac{1}{T_{\sigma}} ; \quad \omega_{n}^{2}=\frac{K_{c} G K_{2}}{R_{s} T_{s} T_{\sigma}} .
$$

Choosing $\xi=0 \cdot 707$, the controller gain is determined as shown in (22). This leads to a current loop of bandwidth equal to $\left(0 \cdot 707 / T_{\sigma}\right)$

$$
K_{c}=\frac{R_{s} T_{s}}{2 G K_{2} T_{\sigma}} .
$$

The $d$-axis controller is designed in a similar fashion.

\subsection{Voltage controller}

With the current controller parameters $T_{c}$ and $K_{c}$ chosen as in (19) and (22), the closed loop transfer function of $q$-axis current loop is as shown below.

$$
\frac{I_{s q}(s)}{I_{s q}^{*}(s)}=\frac{1}{K_{2}} \frac{\left(1+s T_{2}\right)}{\left(1+2 T_{\sigma} s+2 T_{\sigma}^{2} s^{2}\right)} .
$$

The zero at $\left(1 / T_{2}\right)$ due to the current sensor is at a frequency higher than the current loop bandwidth. Hence, this zero can be ignored. Further, the desired voltage loop bandwidth is much lower than the current loop bandwidth. Hence, for the design of voltage controller, the second order term in the denominator polynomial in (23) can also be neglected. Thus, the current loop can be approximated by a first order transfer function shown in (24).

$$
\frac{I_{s q}(s)}{I_{s q}^{*}(s)}=\frac{1}{K_{2}} \frac{1}{\left(1+2 T_{\sigma} s\right)} .
$$

The input-output power balance gives the relationship between $I_{d c}$ and $i_{s q}$ as shown in (25).

$$
I_{d c}=\frac{2}{3} \frac{v_{s q}}{V_{d c}} i_{s q}=K i_{s q} \text { (say). }
$$

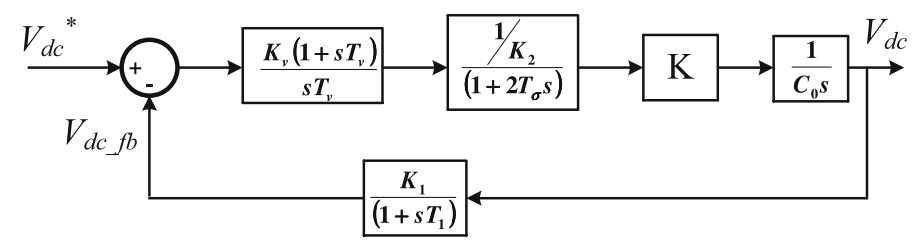

Figure 9. Voltage controller. 


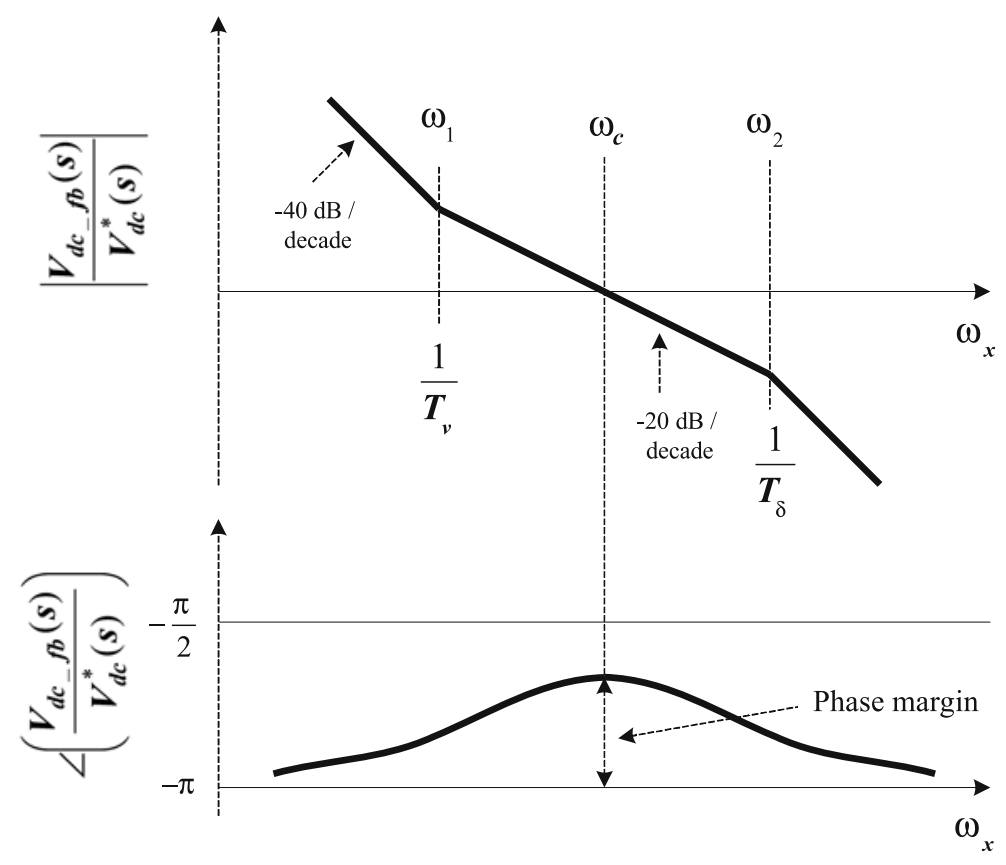

Figure 10. Illustrative bode plot for voltage controller design.

The voltage loop can be represented by a block diagram shown in figure 9 . Here $K_{1}$ and $T_{1}$ are the gain and time constant, respectively, of the voltage sensor; $K_{v}$ and $T_{v}$ are the voltage controller parameters. The open loop transfer function of the voltage loop is defined in (26). Similar to the approximation in (18), the voltage loop transfer function can also be approximated as shown in (26), where $T_{\delta}$ is as defined in (27). Here, $2 T_{\sigma} T_{1}$ is ignored, as it is quite small.

$$
\begin{aligned}
& \frac{V_{d c_{-} f b}(s)}{V_{d c}^{*}(s)}=\frac{K_{e}\left(1+s T_{v}\right)}{s T_{v}\left(1+2 T_{\sigma} s\right)\left(1+s T_{1}\right) C_{0} s} \cong \frac{K_{e}\left(1+s T_{v}\right)}{s^{2} T_{v} C_{0}\left(1+s T_{\delta}\right)} . \\
& K_{e}=\left(\frac{K_{v} K K_{1}}{K_{2}}\right) \text { and } T_{\delta}=2 T_{\sigma}+T_{1} .
\end{aligned}
$$

Since there are two poles at the origin, the magnitude plot of this transfer function has a slope of $-40 \mathrm{~dB} / \mathrm{decade}$ at low frequencies as shown in figure 10 . For system stability, the controller zero $\left(\omega_{1}=1 / T_{v}\right)$ should be located before the unit gain crossover $\left(\omega_{c}\right)$ and the pole $\left(\omega_{2}=1 / T_{\delta}\right)$ should be located after unit gain crossover such that the slope is $-20 \mathrm{~dB} /$ decade at the crossover as shown in figure 10.

The crossover frequency $\omega_{c}$ could be the geometric mean of the two corner frequencies $\left(1 / T_{V}\right)$ and $\left(1 / T_{\delta}\right)$ as shown in (28), where $a$ is any number greater than 1 (Leonhard 2001). Considering a suitable value of $a$, the parameter $T_{v}$ can be chosen as given in (29).

$$
\begin{aligned}
& \omega_{c}=\frac{1}{\sqrt{T_{v} T_{\delta}}}=\frac{1}{a T_{\delta}} \text { (say) } \\
& T_{v}=a^{2} T_{\delta} .
\end{aligned}
$$


Table 2. System and controller parameters.

\begin{tabular}{lccccc}
\hline S. No. & Symbol & Value & S. No. & Symbol & Value \\
\hline 1 & $V_{s}$ & $168(\mathrm{~V})$ & 10 & $K_{1}$ & 0.0011 \\
2 & $L_{s}$ & $660 \mu \mathrm{H}$ & 11 & $T_{1}$ & $10 \mu \mathrm{s}$ \\
3 & $R_{s}$ & $2 \mathrm{~m} \Omega$ & 12 & $K_{2}$ & 0.002 \\
4 & $T_{s}$ & $330 \mathrm{~ms}$ & 13 & $T_{2}$ & $10 \mu \mathrm{s}$ \\
5 & $C_{0}$ & $6750 \mu \mathrm{F}$ & 14 & $K_{c}$ & 5 \\
6 & $G$ & 300 & 15 & $T_{c}$ & $330 \mathrm{~ms}$ \\
7 & $f_{s w}$ & $5 \mathrm{kHz}$ & 16 & $K_{v}$ & 67 \\
8 & $T_{d}$ & $100 \mu \mathrm{s}$ & 17 & $T_{v}$ & $920 \mu \mathrm{s}$ \\
9 & $K$ & 0.396 & 18 & $a$ & 2 \\
\hline
\end{tabular}

The gain at crossover frequency $\omega_{c}$ is equal to one as shown in (30). Using equations (27-30), the parameter $K_{v}$ can be selected as given in (31).

$$
\begin{aligned}
& \left|\frac{V_{d c_{-} f b}(s)}{V_{d c}^{*}(s)}\right|_{\omega_{x}=\omega_{c}}=1=\frac{K_{e} \sqrt{1+\left(\omega_{c} T_{v}\right)^{2}}}{\omega_{c}^{2} C_{0} T_{v} \sqrt{1+\left(\omega_{c} T_{\delta}\right)^{2}}} \\
& K_{v}=\frac{C_{0} K_{2}}{K_{1} K a T_{\delta}} .
\end{aligned}
$$

Considering $a=2$, the phase margin is given by (32).

$$
\text { Phase margin }=\left(\tan ^{-1}\left(\omega_{c} T_{v}\right)-\tan ^{-1}\left(\omega_{c} T_{\delta}\right)\right)=\left(\tan ^{-1} a-\tan ^{-1} \frac{1}{a}\right)=37^{\circ} .
$$

The system parameters are presented in table 2 . The controller parameters are calculated as explained earlier. They are also listed in the table.

In order to verify the validity of the approximations in (18), the bode plots of the actual as well as approximated open loop transfer functions of the current loop are plotted as shown in figure 11 .

Similarly, to verify the validity of the approximations in (24) and (26) while designing the voltage controller, the bode plots of the actual and approximate open loop transfer functions of the voltage loop are plotted as shown in figure 12 .

As seen, the approximations, which simplify the design calculations, do not introduce any significant error in the gain and/or phase angle over frequencies of interest.

\section{Simulation and experimental results}

A 250-kVA vector-controlled FEC is simulated with MATLAB/SIMULINK. The system parameters are shown in table 2. Sine-triangle PWM method is employed with a carrier frequency of $5 \mathrm{kHz}$.

Figure 13 shows the dynamic response of line current during a change in load from $10 \%$ to $30 \%$ at $t=1.1 \mathrm{~s}$. The steady state power factor is close to unity and the dynamic response is found to be good. The transient response for a change in the reactive power reference $\left(i_{s d}^{*}\right)$ 


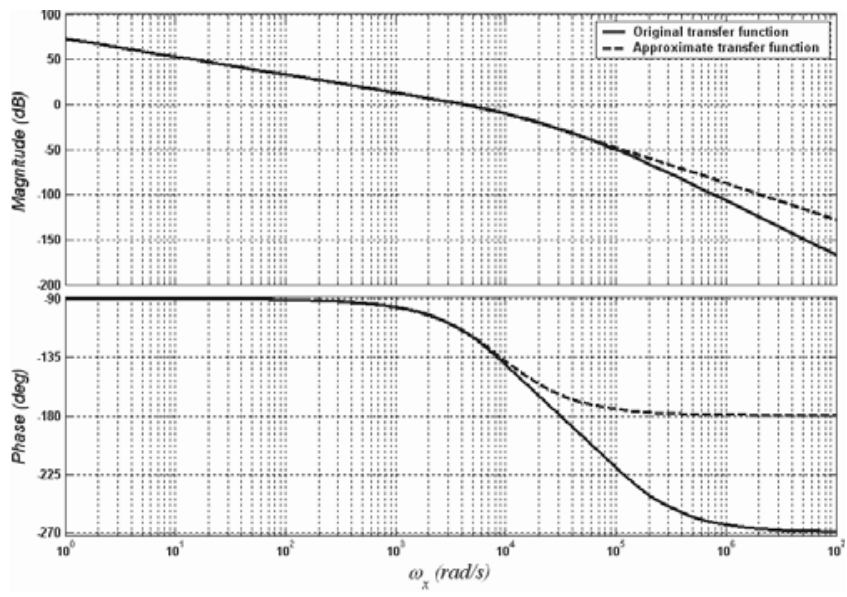

Figure 11. Bode plots of actual and approximate open loop transfer functions of the current loop.

from 0 to $10 \%$ is also fast as seen from figure 14 . For $t>0.8 \mathrm{~s}$, the power factor is close to zero since only reactive power is drawn.

The experimental set-up consists of a 250-kVA IGBT converter with TMS320LF2407 DSP based digital controller (Texas Instruments 1990). The parameters of the system are the same as those for the simulation. Figure 15 shows the line current and the mains voltage with a $6 \mathrm{~kW}$ resistive load. The current is highly distorted, since the load on the converter is less than $2.5 \%$ of full load. When the reactive power reference is set to $25 \mathrm{kVA}$, the wave shape of line current is better, since the current is close to $10 \%$ of the rated value as shown in figure 16 .

It is difficult to load the converter up to the rated load of $250 \mathrm{kVA}$ due to limitations of the source as well as the loading arrangement. Testing at full load requires connecting two such converters in a back-back fashion, one sourcing power from the mains and the other feeding the power back to the mains (Ghosh 2007). This converter is proposed to be employed in a circulating power network of converters and electrical machines with only the losses drawn from the mains.

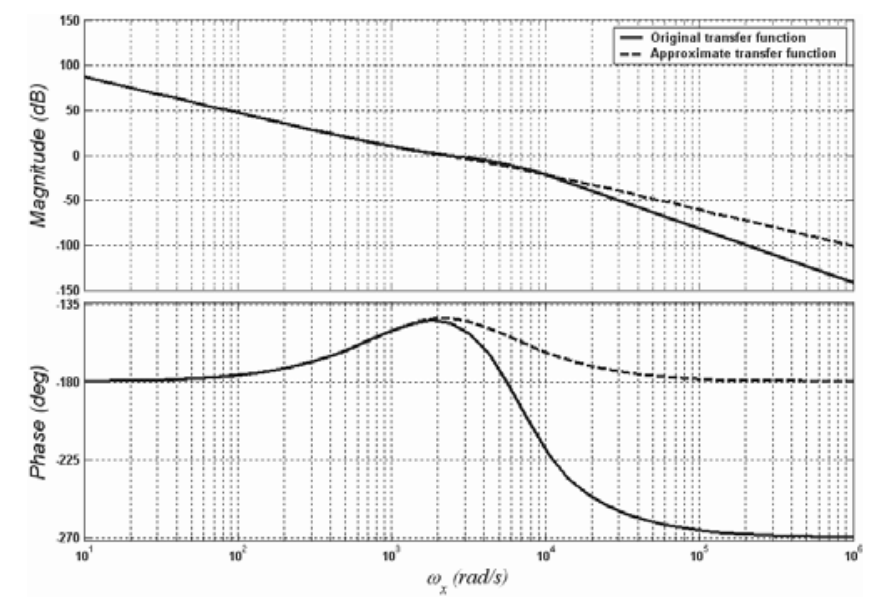

Figure 12. Bode plots of actual and approximate open loop transfer functions of the voltage loop. 

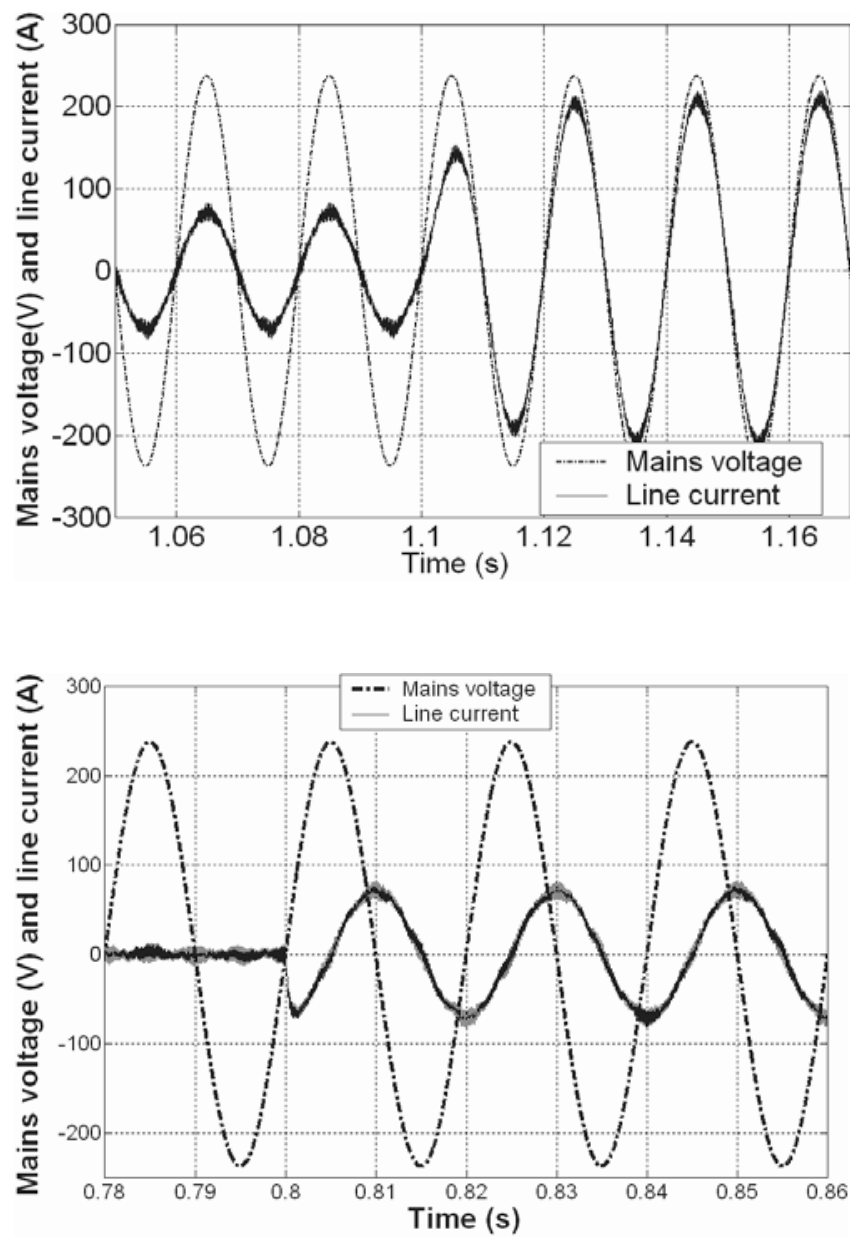

Figure 13. Transient response of line current for a step change in load (active power).

Figure 14. Transient response of line current for a step change in reactive power reference.

\section{Starting process of FEC}

The ac side per-phase fundamental equivalent circuit of an FEC is shown in figure 17. The converter pole voltage averaged over a carrier cycle can be represented by a sinusoidal voltage $V_{i}$ at grid frequency. From figure 17 it is clear that the line currents are decided by the voltage

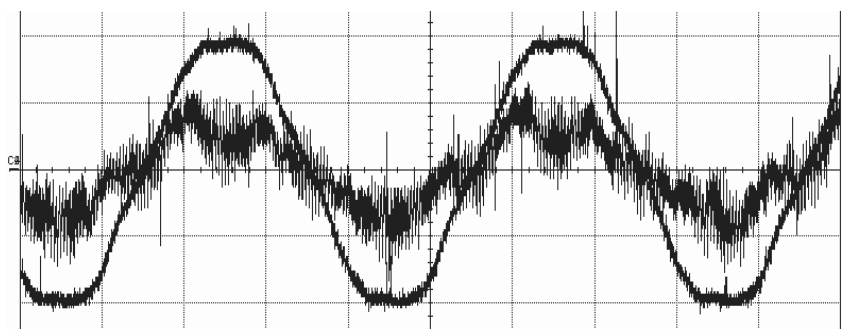

Figure 15. Mains voltage $(125 \mathrm{~V} /$ division) and line current $(25 \mathrm{~A} /$ divison $)$ with a $6 \mathrm{~kW}$ resistive load: experimental result. 


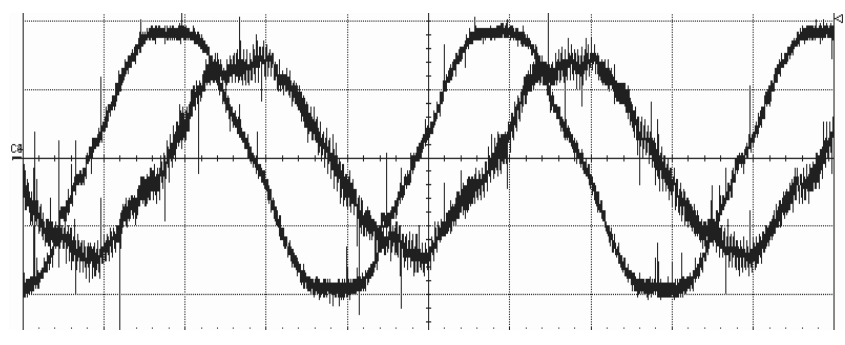

Figure 16. Mains voltage $(125 \mathrm{~V} /$ division) and line current $(50 \mathrm{~A} /$ division $)$ with $10 \%$ reactive power $(25 \mathrm{kVA})$ : experimental result.

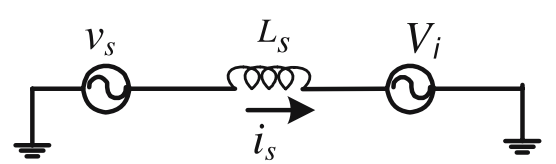

across the filter inductor and also by the value of filter inductor $\left(L_{s}\right)$ itself. During starting, there could be a large difference between the supply voltage and the average pole voltage of the converter. This results in high starting currents.

This problem of high starting currents is more pronounced for high power FEC. At the same voltage level, as the power level of converter increases, the rated current increases. So, the base impedance decreases. Hence, for a given percentage of filter reactance, $L_{s}$ decreases as the power rating increases. So, the starting current problems become more severe at high power levels. Different methods to reduce the starting currents are discussed below.

\subsection{Pre-charging of DC bus}

During start-up, the dc bus voltage is equal to zero. Hence, the pole voltages of the converter are also equal to zero. So, total supply voltage is applied across the line inductors, and the line currents increase abnormally.

To mitigate this problem, the dc bus is usually pre-charged to peak line-line voltage by operating the converter as a diode rectifier. In this process pre-charging resistors are connected
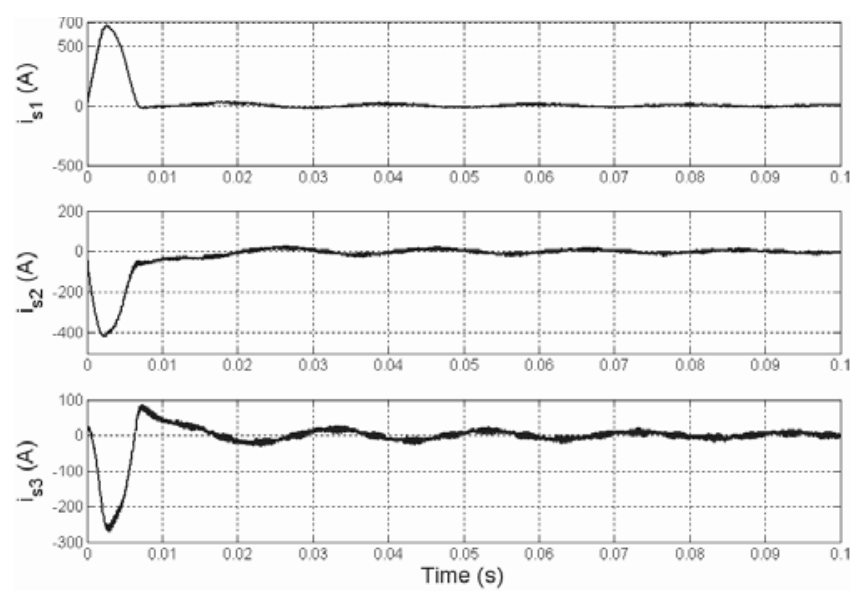

Figure 18. Starting current transient of FEC. 


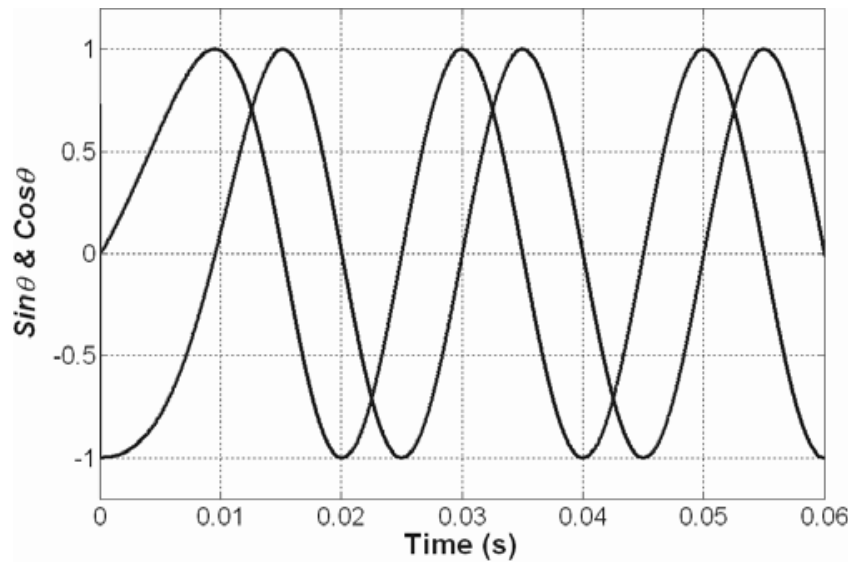

Figure 19. Transients in unit vector generation.

in series with the line inductors to limit the currents (Finney 1988; Gilmore \& Skibiniski 1996; Wijenayake et al 1997). Once pre-charging is completed, the series resistances are by-passed.

Since the dc bus is pre-charged, the average pole voltage applied can be considerably high. This reduces the starting currents significantly when gate pulses to the devices are released. Figure 18 shows the starting currents of FEC with DC bus pre-charged to peak line-line of supply voltage. Sine-triangle PWM method is employed. It can be observed that the peak value of starting current is abnormally high (close to $700 \mathrm{~A}$ ) despite pre-charging. The reasons are analysed and solutions are explained in the following sections.

\subsection{Unit-vector dynamics}

The control scheme requires transformations between stationary and revolving reference frames. This, in turn requires $\cos \theta$ and $\sin \theta$ values as described in $\S 2$. The unit vector generation involves low-pass filters, and hence considerable dynamics and settling time. This is brought out by the simulation result in figure 19. If the controller is initiated before unitvector reaches steady state, the angle $\theta$ (see figure 4) is erroneous. Consequently, controller generates references that are inappropriate, leading to high starting currents as shown in figure 18. Hence, to limit the starting currents, the control algorithm is to be initiated only after the unit-vector reaches steady state. With this modification in starting process, the line currents are as shown in figure 20. While the peak starting current has reduced, it is still unacceptably high (close to $600 \mathrm{~A}$ ).

\subsection{Low-pass filter in voltage reference path}

As seen from the block diagram of the controller shown in figure 7, the error between the dc bus reference and the measured dc voltage is fed to the voltage controller, which provides the current reference $i_{s q}^{*}$. When the control algorithm is initiated, the reference voltage is equal to the set value and the measured voltage is equal to the peak line-line voltage. Voltage error is quite high. Hence the current reference is also high. The controller may even saturate because of this large error, causing large transient current.

To overcome this problem, the dc bus reference is increased gradually from its initial value (essentially equal to the peak line-line voltage) to its final value over a period of time. This duration is much larger than the voltage loop time constant. To meet the above objective, the dc bus reference signal is passed through a low-pass filter as shown in figure 21 before feeding 

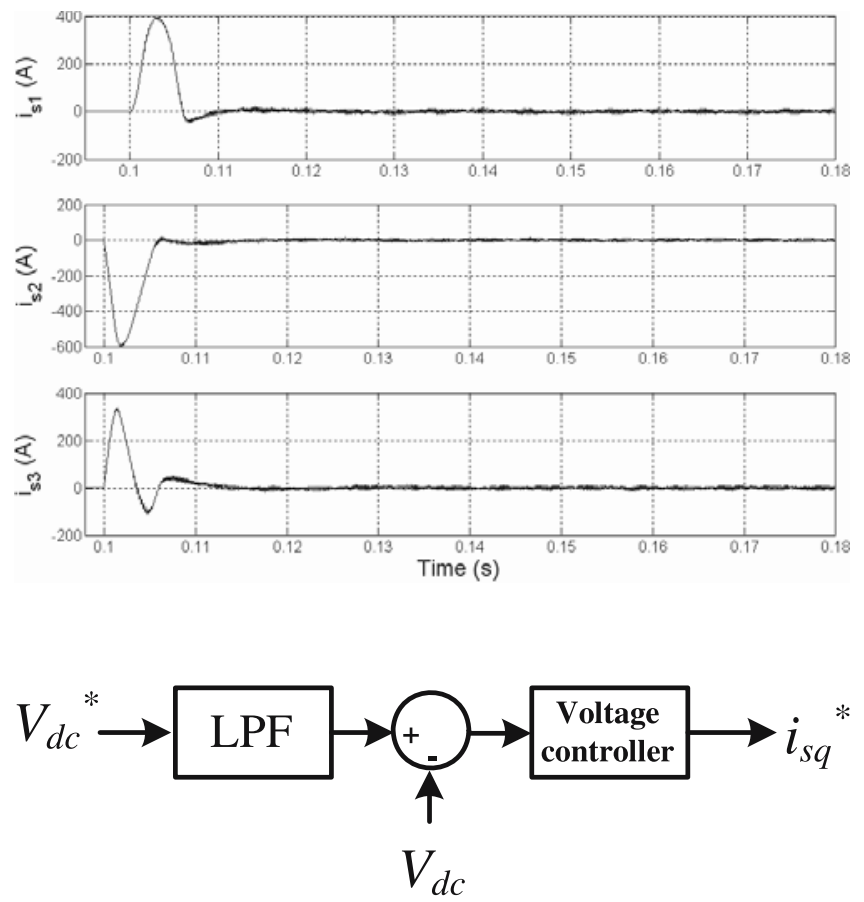

Figure 20. Starting current transient: Controller initiated after unit-vector reached steady state.

Figure 21. Low-pass filtering of dc voltage reference to reduce starting current transients.

it to the controller. With this filter, the reference to the voltage controller changes slowly. The voltage controller tracks the reference closely and the error is quite low throughout the start-up process. As the error is low, starting currents are also low. But, the low-pass filter slows down the response time of FEC with changes in DC bus reference. Throughout this starting process, the reactive power reference is kept at zero. The starting currents are reduced significantly (peak value around $60 \mathrm{~A}$ ) as seen from figure 22 . The peak starting current is much higher than the steady-state peak no-load current.
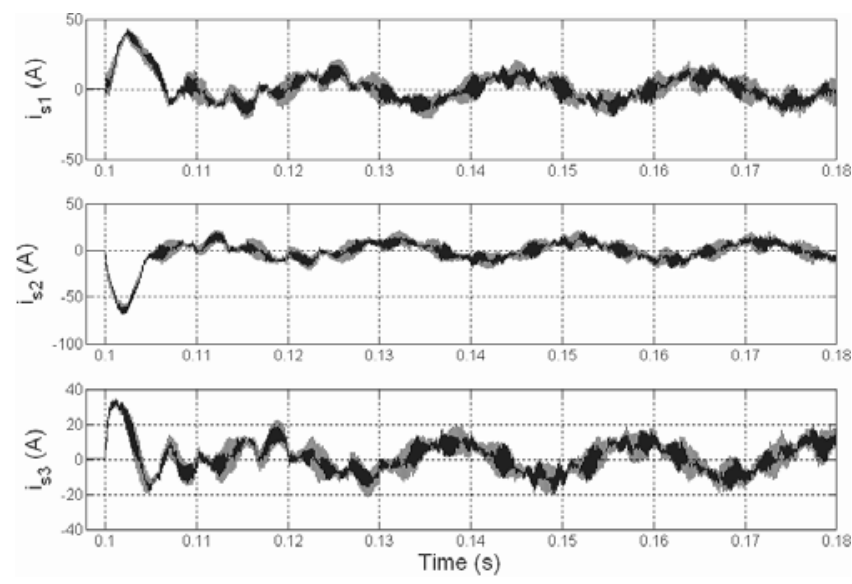

Figure 22. Starting current transient: Controller initiated after unit-vector reached steady state, LPF inserted in $V_{d c}^{*}$ path. 

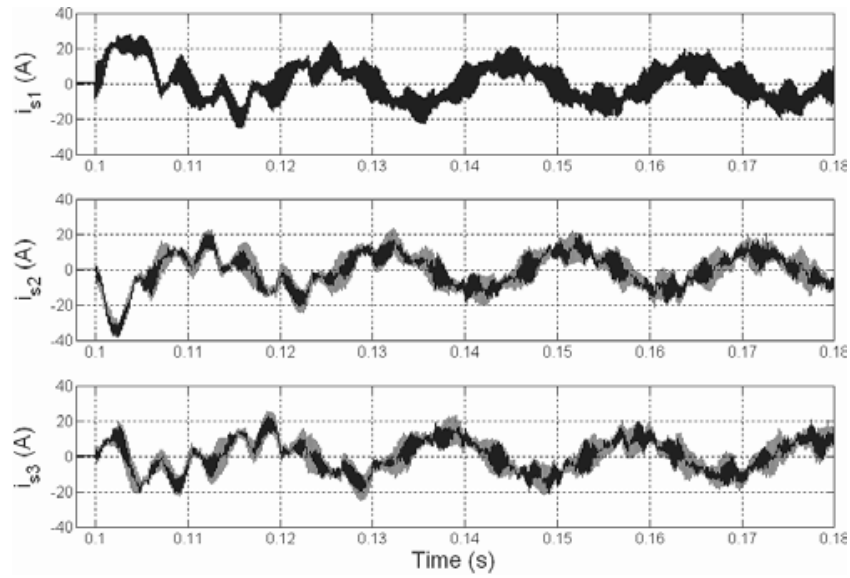

Figure 23. Starting current transient: Controller initiated after unit-vector reached steady state, LPF inserted in $V_{d c}^{*}$ path, $G$ varied dynamically.

\subsection{Dynamic variation of inverter gain}

To limit the starting current, the average pole voltage is required to be close to the mains voltage through out the start-up process. The average pole voltage applied is determined by the references $v_{q}^{*}$ and $v_{d}^{*}$ as shown in figure 7 . In addition to the outputs of current controllers, these references also depend on the feed-forward terms $\left(v_{q f f}\right.$ and $\left.v_{d f f}\right)$ as seen from figure 7. The feed-forward terms depend on the inverter gain $G$ as shown by (15). While the gain $G$ is a constant during steady state, it actually varies during starting process due to variation in $V_{d c}$. Hence, instead of holding $G$ constant at its nominal steady state value as in figure 22, it could be varied dynamically using the measured value of $V_{d c}$. This leads to reduction in starting current (peak value $<40 \mathrm{~A}$ ) as shown in figure 23 .

\subsection{Modulation methods}

Pre-charging ensures that the initial dc bus voltage is equal to peak line-line voltage i.e. $\sqrt{6} V_{s}$. Now, just after pre-charging, the highest average phase voltage that can be applied is $0.5 * V_{d c}$ or $\sqrt{\frac{3}{2}} V_{s}$ with sine-triangle PWM (Varma \& Narayanan 2006). This is less than the peak value of mains voltage, i.e. $\sqrt{2} V_{s}$. Hence, whenever a phase voltage is close to its peak, the converter average pole voltage is significantly less than the mains voltage. In other words the average applied voltage vector has lesser magnitude than the mains voltage vector. Hence, the modulator saturates and goes into over modulation as demonstrated by the three-phase reference voltages during starting, presented in figure 24 .

Instead of sine-triangle PWM, if space vector pulse width modulation (SVPWM) is used, the highest average phase voltage that can be applied is equal to $V_{d c} / \sqrt{3}$ (Varma \& Narayanan 2006). This is equal to the peak value of supply voltage. Hence, without going into overmodulation, the required average phase voltage can be applied. In space vector terms, the average applied voltage vector could equal the mains voltage vector in any carrier cycle since the start of control execution. Figure 25 shows the three-phase reference voltages with space vector PWM during starting. It is clear from this figure that the modulator is not landing into over modulation and is almost in linear modulation.

The average pole voltage applied being close to the mains voltage over the entire line cycle throughout the starting process is likely to ensure that the starting currents are quite low. This 

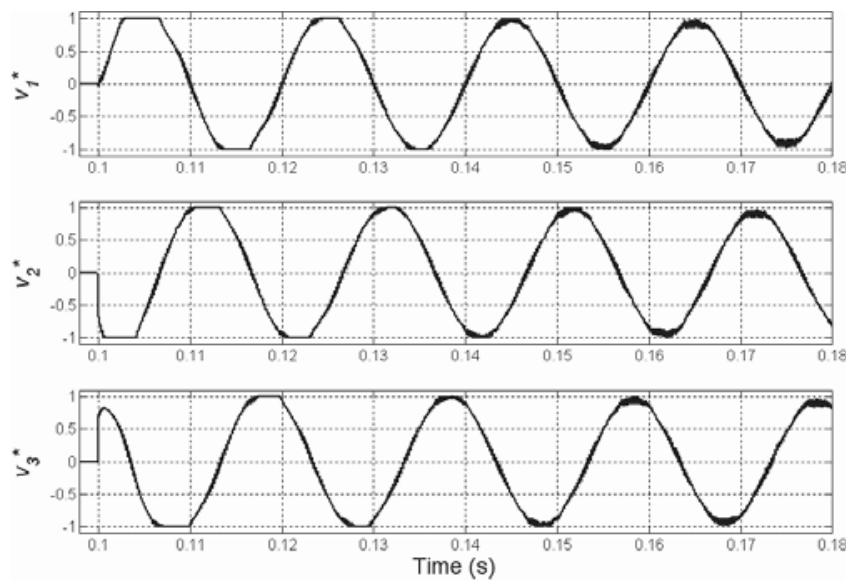

Figure 24. Three-phase modulating waveforms during starting, Sine-triangle PWM.

is seen from figures 26 and 27, which present the starting transients with space vector PWM for constant and dynamic inverter gain, respectively.

When $G$ is held constant, the peak starting current with space vector PWM is considerably less than with sine-triangle PWM as seen from figures 22 and 26. Similar improvement can also be seen with space vector PWM when $G$ is varied dynamically. In fact, with dynamic variation of $G$ the peak starting current with space vector PWM is quite close to the peak steady state value as seen from figure 27 .

In this work, the average of the sum of the maximum and the minimum modulating signals is subtracted from the original three-phase modulating signals to generate reference signals equivalent to space vector PWM (Varma \& Narayanan 2006).

The space vector PWM method adds zero sequence voltage to the three phase pole voltages. In back-back connected converters, this zero sequence voltage can cause zero sequence currents circulating between the converters. Hence, this method is not suitable for back-back testing of converters.
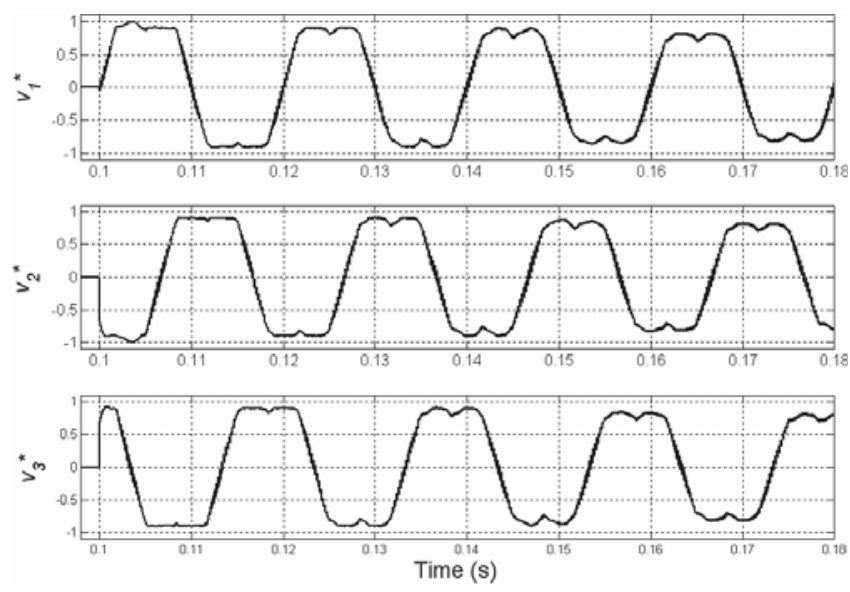

Figure 25. Three-phase modulating waveforms during starting, space-vector PWM. 

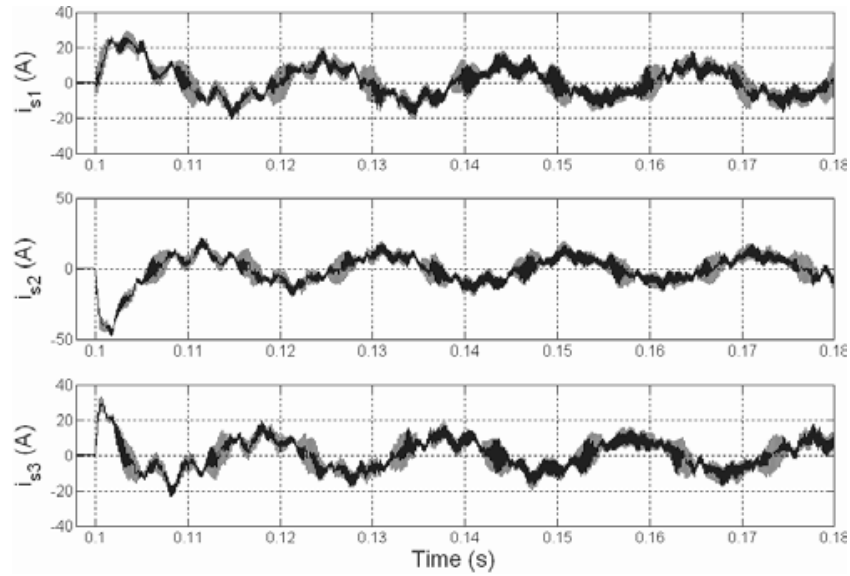

Figure 26. Starting current transient: Controller initiated after unit-vector reached steady state, LPF inserted in $V_{d c}^{*}$ path, Space vector PWM.

\subsection{Variation of filter inductance}

In order to verify the effectiveness of the starting process for various values of line inductance, simulations are repeated with a filter inductor $L_{s}=330 \mu \mathrm{H}$. Figures 28 and 29 present the starting currents with sine-triangle and space vector PWM, respectively, and with dynamic variation of inverter gain $G$. These two figures can be compared with figures 23 and 27 respectively. The peak currents are increased as the filter inductor value is reduced. But still they are within acceptable limits.

\subsection{Experimental verification}

Figure 30 shows the experimental results of starting transients in the line current with the control initiated after the unit vector generation attains steady state $\left(L_{s}=660 \mu \mathrm{H}\right)$. As seen in this figure, the peak currents are quite low (peak $\approx 45 \mathrm{~A}$ ). Dynamic adjustment of the inverter gain $G$ leads to further reduction in transients, though marginal, as shown in figure 31 with same $L_{s}$ (peak $\left.\approx 30 \mathrm{~A}\right)$.
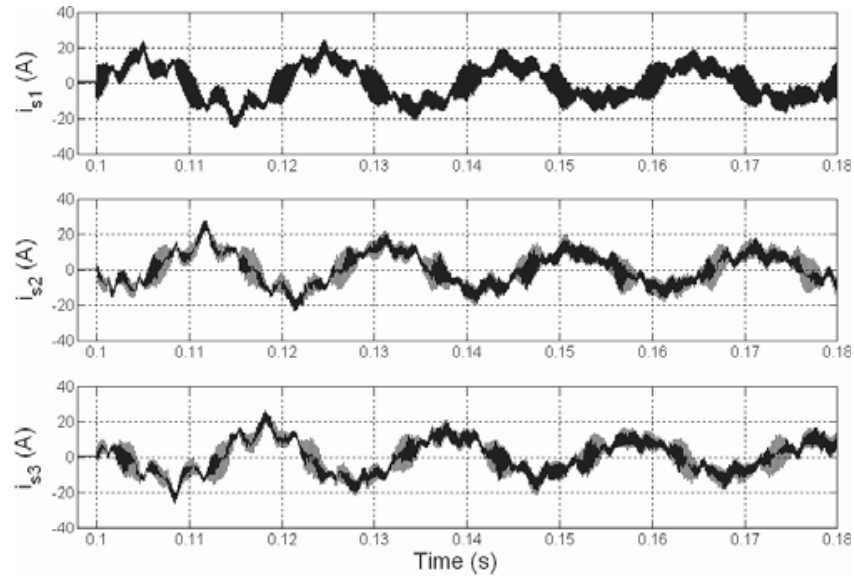

Figure 27. Starting current transient: Controller initiated after unit-vector reached steady state, LPF inserted in $V_{d c}^{*}$ path, $G$ varied dynamically, Space vector PWM. 

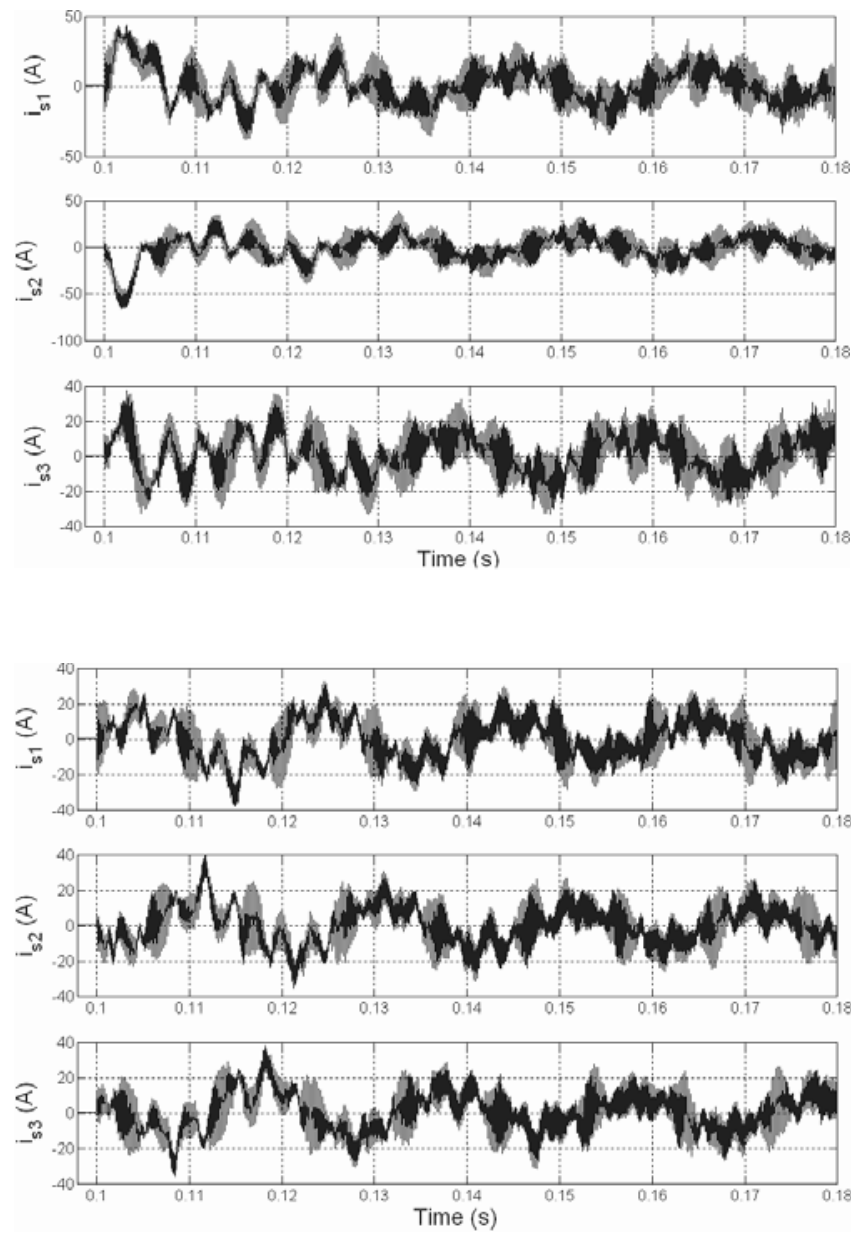

Figure 28. Starting current transient: Controller initiated after unit-vector reached steady state, LPF inserted in $V_{d c}^{*}$ path, $G$ varied dynamically, Sine - triangle $\mathrm{PWM}, L_{s}=330 \mu \mathrm{H}$.

Figure 29. Starting current transient: Controller initiated after unit-vector reached steady state, LPF inserted in $V_{d c}^{*}$ path, $G$ varied dynamically, Space vector PWM, $L_{s}=330 \mu \mathrm{H}$.

The measured starting current transients for $L_{s}=330 \mu \mathrm{H}$ with constant $G$ and dynamically adjusted $G$ are presented in figures 32 and 33, respectively. Due to small filter inductance, the starting transients in these figures are higher than those in figures 30 and 31 . However, the starting procedure ensures that the transient currents are within the acceptable limits.

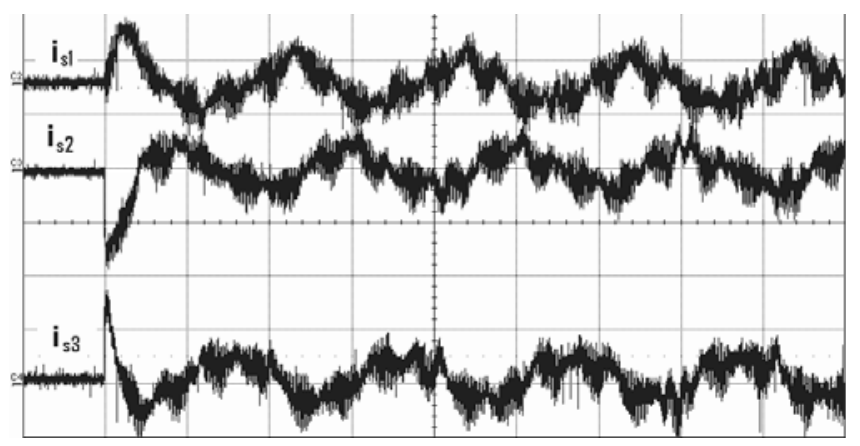

Figure 30. Starting current transient with $G$ maintained constant $(25 \mathrm{~A} /$ division $)\left(L_{s}=660 \mu \mathrm{H}\right)$ : experimental result. 

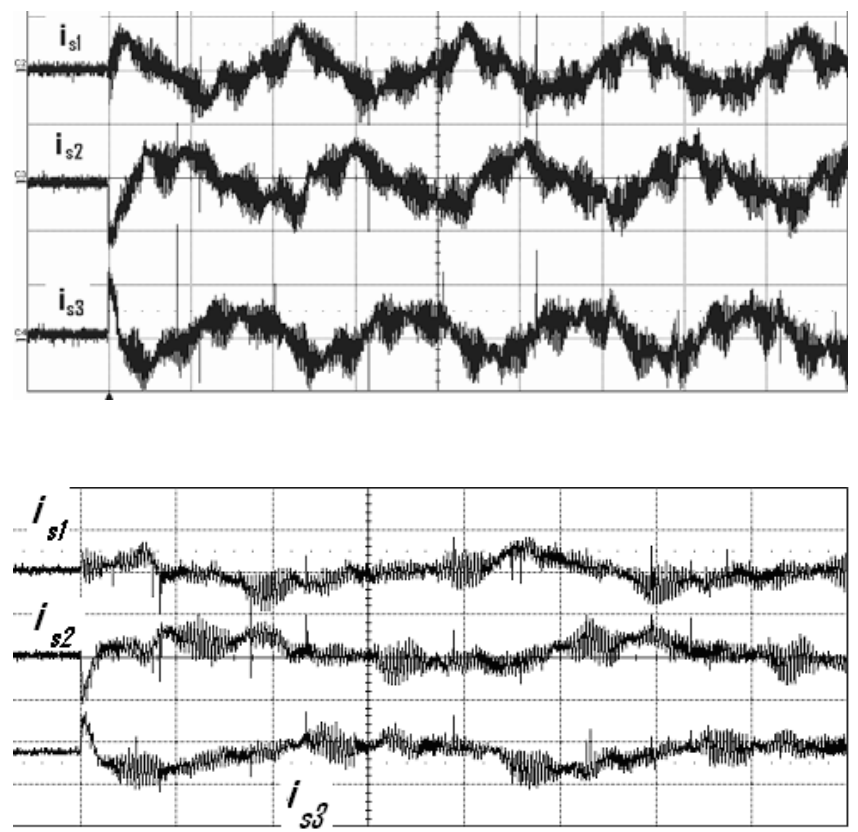

Figure 31. Starting current transient with $G$ varied dynamically ( $25 \mathrm{~A} /$ division). $\left(L_{s}=660 \mu \mathrm{H}\right)$ : experimental result.

Figure 32. Starting current transient with $G$ maintained constant $(50 \mathrm{~A} /$ division $)\left(L_{s}=330 \mu \mathrm{H}\right)$ : experimental result.

From the above results it can be observed that pre-charging of dc bus, starting the control execution only after unit-vector reaches steady state and inserting a low-pass filter in the dc voltage reference path are essential to reduce the peak of starting current to an acceptable level. The peak of the starting current can be reduced further by dynamically varying the inverter gain $G$. When injection of common mode voltage is acceptable, space vector PWM can be employed for further reduction in starting current.

\section{Conclusion}

Vector control was implemented on a $250 \mathrm{kVA}$ front-end converter. Simulation and experimental results were presented. A simple and straightforward algorithm for unit vector generation was proposed, and the results were satisfactory. The problem of starting current transient was more pronounced for high power FEC, where the value of filter inductor was very small. A safe starting procedure to limit the starting current transients was evolved. The starting

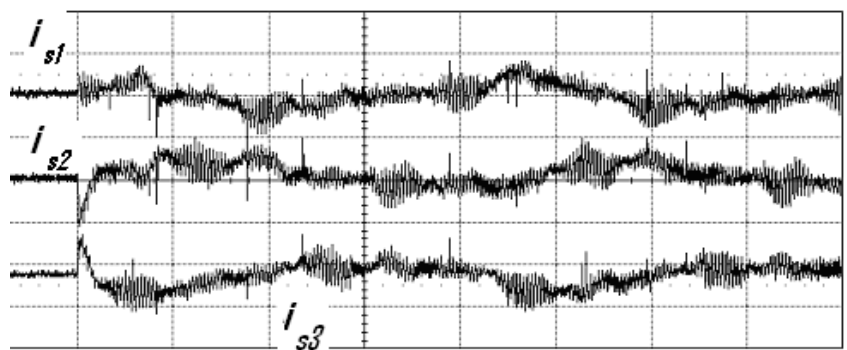

Figure 33. Starting current transient with $G$ varied dynamically $(50 \mathrm{~A} /$ division $)\left(L_{s}=330 \mu \mathrm{H}\right)$ : experimental result. 
procedure included pre-charging of the dc bus, beginning the control execution after the unit vector generation reached steady state and inserting a low-pass filter in the dc bus reference path. The work has resulted in an improved understanding of the starting transient and its mitigation in line-side converter.

\section{References}

Chattopadhyay S, Ramanarayanan V 2005 A voltage-sensorless control method to balance the input currents of a three-wire boost rectifier under unbalanced voltage condition. IEEE Trans. Ind. Electron. IE-52: 386-398

Chung S K 2000 Phase locked loop for grid-connected three-phase power conversion system. Proc. IEE Electr. Power Appl. 147(3): 213-219

Finney D 1988 Variable Frequency AC Motor Drive System. London: Peter Peregrinus Ltd.

Ghosh R 2007 Modelling, Analysis and Control of Single-phase and Three-phase PWM Rectifiers. $\mathrm{Ph} . \mathrm{D}$ Thesis, Indian Institute of Science, Bangalore, May 2007

Gilmore W, Skibiniski G 1996 Pre-charge circuit utilizing non-linear firing angle control. Conf. Rec. IEEE-IAS Annu. Meeting 2: 1099-1105

Leonhard W 2001 Control of Electrical Drives. 3rd ed., Springer International Edition

Noguchi T, Tomki H, Kondo S, Takahashi I 1998 Direct power control of PWM converter without power-source sensors. IEEE Trans. Ind. Appl. 52: 476-479

Ranganathan V T 2007 Lecture Notes on Electric Drives. Electrical Engineering Dept., Indian Institute of Science, Bangalore

Texas Instruments 1990 TMS320LF/LC240X DSP Controllers Reference Guide (SPRU357)

Varma P S, Narayanan G 2006 Space vector PWM as a modified form of sine-triangle PWM for simple analog/digital implementation. IETE Journal of Research 52(6): 435-449

Wijenayake A H, Gilmore T, Lukaszewski R, Anderson D, Waltersdorf G 1997 Modelling and analysis of shared/common DC bus operation of AC drives. Conf. Rec. IEEE-IAS Annu. Meeting 1: 599-604 